
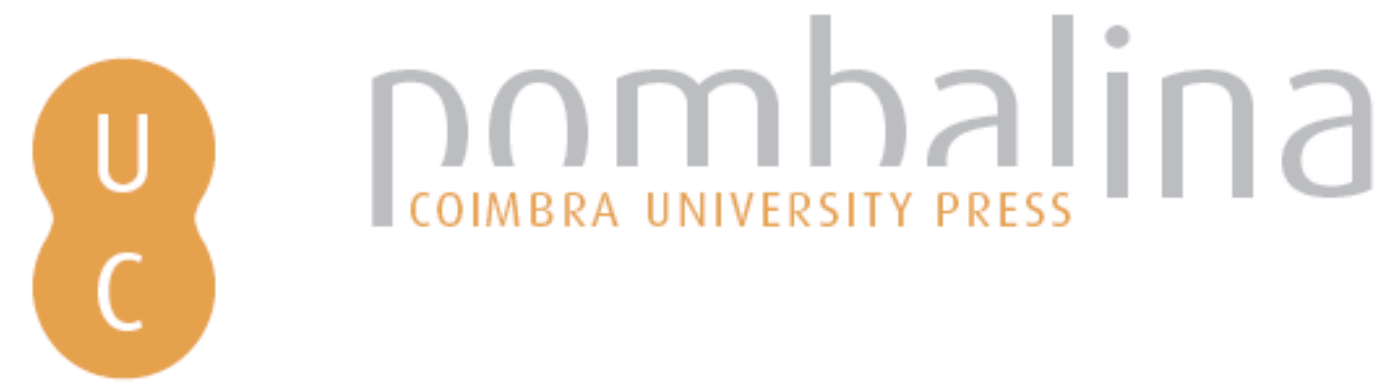

\title{
Contributos para o estudo das fontes clássicas na produção de gárgulas em contexto quinhentista em Portugal
}
Autor(es):
Barreira, Catarina
Publicado por: $\quad \begin{aligned} & \text { Associação Portuguesa de Estudos Clássicos; Centro de Estudos } \\ & \text { Clássicos e Humanísticos; Imprensa da Universidade de Coimbra }\end{aligned}$
persistente:
DOI:
URI:http://hdl.handle.net/10316.2/31564
DOI:http://dx.doi.org/10.14195/978-989-8281-69-2_20
Accessed : $\quad$ 26-Apr-2023 09:14:53

A navegação consulta e descarregamento dos títulos inseridos nas Bibliotecas Digitais UC Digitalis, UC Pombalina e UC Impactum, pressupõem a aceitação plena e sem reservas dos Termos e Condições de Uso destas Bibliotecas Digitais, disponíveis em https://digitalis.uc.pt/pt-pt/termos.

Conforme exposto nos referidos Termos e Condições de Uso, o descarregamento de títulos de acesso restrito requer uma licença válida de autorização devendo o utilizador aceder ao(s) documento(s) a partir de um endereço de IP da instituição detentora da supramencionada licença.

Ao utilizador é apenas permitido o descarregamento para uso pessoal, pelo que o emprego do(s) título(s) descarregado(s) para outro fim, designadamente comercial, carece de autorização do respetivo autor ou editor da obra.

Na medida em que todas as obras da UC Digitalis se encontram protegidas pelo Código do Direito de Autor e Direitos Conexos e demais legislação aplicável, toda a cópia, parcial ou total, deste documento, nos casos em que é legalmente admitida, deverá conter ou fazer-se acompanhar por este aviso.

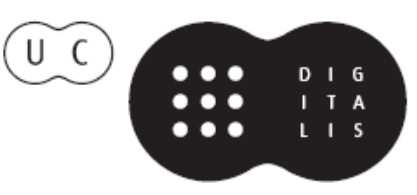




\section{Espaços e Paisagens}

Antiguidade Clássica

e Heranças Contemporâneas

Vol. III

Francisco Oliveira, Jorge Oliveira e Manuel Patrício

IMPRENSA DA UNIVERSIDADE DE COIMBRA 


\title{
CONTRIBUTOS PARA O ESTUDO DAS FONTES CLÁSSICAS NA PRODUÇÃO DE GÁRGULAS EM CONTEXTO QUINHENTISTA EM PORTUGAL
}

\author{
CATARINA BARREIRA \\ Bolseira da FCT
}

\begin{abstract}
: contributions for the study of classic sources in the production of figurative gargoyles in the Portuguese context of the sixteenth century
\end{abstract}

Our research concerns gargoyles as elements of monumental sculpture, integrated in religious buildings that played an important pedagogical and symbolic role from the 13th century to the 16th century. Characteristic of the Central European Gothic, gargoyles reached their apogee in the national context in the first half of the 16th century, a phenomenon for which two things contributed a great deal: the first is related to the conventual complex of Santa Maria da Vitória, Batalha, where gargoyles can be seen in all the construction, with an iconographic program unknown among us until then. The second is the presence, in Portugal, of a very significant number of artists proceeding from other countries, who were acquainted with its existence in buildings. Therefore, in the first quarter of the 16th century, a significant number of religious buildings have gargoyles, but the phenomenon of their integration and the legitimating of their iconographic programs will have continuity in buildings where classical trends can be detected. Our presentation reflects upon gargoyles sculpted under Renaissance inspiration, upon the classic aesthetic principles, revealing an important process of formal and thematic update, but also revealing some formal and iconographic persistence that will originate very special gargoyles, in particular the sculptured gargoyles made by French sculptor João de Ruão for the Manga's Cloister, in Coimbra.

Keywords: artistic persistence's, artistic news, gargoyles, Gothic, Manuelino, iconographic program, Renaissance

Palavras-chave: formas, gárgulas, Gótico, Manuelino, persistências e novidades, programas iconográficos, Renascimento e Classicismo.

\section{Introdução}

O trabalho que nos encontramos a desenvolver reflecte sobre as gárgulas figurativas enquanto elementos da escultura monumental, integradas em edifícios religiosos, que, do século XIII ao século XVI, desempenharam importantes funções, quer em termos pedagógicos, quer em termos simbólicos. Poucas vezes atraíram a atenção dos nossos historiadores de arte e talvez por isso ainda estejam por fazer os levantamentos históricos e artísticos dos edifícios nacionais onde se articulem os vários programas iconográficos 
presentes na escultura monumental com outras formas artísticas como os vitrais, os retábulos, os cadeirais, etc.

A marginalização das gárgulas face aos programas iconográficos e a produção de um discurso epidérmico que as ligou a aspectos pagãos e populares, frutos do livre arbítrio dos imaginários, retirou-lhes o carácter erudito que caracteriza uma boa percentagem das mesmas e a complexidade de alguns conjuntos. Por outro lado, fomentou-se a ligação das gárgulas a um tipo de marginalia resultante de uma fuga ao controlo iconográfico. A ser verdade, este mito anularia a principal função das gárgulas, que é a função pedagógica. Esta vocação pedagógica estabeleceu uma importante ponte com os sermões edificantes, com a literatura moralizante e com a "devotio moderna".

Em articulação com estes aspectos está o facto de as gárgulas demonstrarem de uma forma evidente a actualização dos seus autores no que concerne ao contexto da época: os melhores exemplos são as gárgulas 'índio' em Sta. $\mathrm{M}^{\mathrm{a}}$ da Vitória, pertencentes à coordenação de Mateus Fernandes e a gárgula 'rinoceronte' do claustro de Sta. $\mathbf{M}^{\mathrm{a}}$ de Alcobaça, fruto das intervenções de João de Castilho.

\section{As fontes}

Convém esclarecer desde já o que entendemos como fonte ou modelo para a realização de gárgulas. É algo bastante complexo, que articula diversos aspectos da produção artística deste tipo de escultura monumental, que vão logo desde o modo como o artista se integrou na sua época e com as mentalidades, ou seja, de que modo e porquê o artista foi influenciado pelo tecido social envolvente (religioso, artístico, cultural, económico, etc.). Não nos devemos esquecer que o processo de produção das gárgulas, para além desta componente que retirou ou não inspiração do contexto, resultou também em grande parte do percurso pessoal do artista, da sua bagagem visual, da sua imaginação e criatividade, em articulação com a aquisição de competências técnicas e tecnológicas. A partir de alguns cadernos de obras (Sta. $\mathbf{M}^{\mathrm{a}}$ de Belém, Sta. Cruz de Coimbra) lavrar gárgulas era um ofício especializado: os lavrantes dedicavam-se, em paralelo, a outras formas de escultura monumental e de vulto, como foi o caso de João de Ruão. Significativo foi também o papel dos mecenas para quem os artistas trabalhavam, que tinham uma palavra a dizer na delineação dos programas e dos temas. Por último, outro aspecto não menos importante foi a articulação dos temas representados com os destinatários, ou seja, o artista produtor de gárgulas soube distinguir os diferentes tipos de públicos - alvo e realizar programas de acordo com essa distinção. Neste âmbito, temos dois exemplos: os programas claustrais de Sta. $\mathrm{M}^{\mathrm{a}}$ de Belém e de Sta. $\mathbf{M}^{\mathrm{a}}$ de Alcobaça são diferentes, em termos temáticos, das gárgulas do exterior.

\section{As gárgulas em contexto quinhentista}

Apesar da colocação de gárgulas figurativas em edifícios religiosos ter tido o seu início entre nós no séc. XIII, as gárgulas tiveram o seu apogeu em 
contexto nacional no primeiro quartel do século XVI, fenómeno para o qual muito contribuíram dois factores. O primeiro diz respeito a Sta. $\mathrm{M}^{\mathrm{a}}$ da Vitória, onde as gárgulas, resultantes de várias campanhas e diferentes coordenações, pontuam toda a edificação, num programa iconográfico até então inédito entre nós e que recorreu a um grande e diversificado conjunto de fontes. O estaleiro batalhino espelha a evolução formal e temática das gárgulas em território nacional.

O segundo factor foi a presença, no nosso país, de um número muito significativo de artistas provenientes de outros países, familiarizados com a sua realização e colocação e, em paralelo, responsáveis pela sua renovação em termos formais e temáticos. Este fenómeno designa-se por "nomadismo artístico" e foi introduzido na historiografia artística em Portugal pela mão do professor João Barreira (1866-1961) ${ }^{1}$ questão à qual demos algum seguimento. ${ }^{2}$ A "bagagem visual" destes artistas trouxe contributos significativos para o nosso panorama artístico, mas constituiu-se como um processo duplo, pois os "nómadas" também se adaptaram à nossa escala, aos materiais e ao gosto dos comitentes. Conjuntamente, a presença de obras de arte e de tratados, oriundos do exterior, enriqueceram e dilataram o panorama artístico e, por isso, foram igualmente uma forma de "nomadismo artístico".

Assim, no primeiro quartel de quinhentos uma percentagem significativa de edificações religiosas exibia gárgulas integradas num fenómeno complexo de saturação ornamental que misturou elementos do gótico (o que constituiu um interessante caso de persistência artística) com a introdução de novidades, os elementos "à romano". Esta mescla, contribuiu para o despoletar do processo da dissolução da decoração gótica e tardo-gótica, em prol de uma crescente familiarização com algum vocabulário clássico, durante o período que, em termos cronológicos corresponde, grosso modo, ao reinado de D. Manuel, ou seja, o fenómeno da decoração "à romano" precedeu, em algumas décadas, a arquitectura renascença e os princípios estruturais clássicos.

A tendência para a mudança no panorama ocorreu a partir da subida ao trono de D. João III, embora mantendo a importância do papel desempenhado pelo "nomadismo artístico", pois tínhamos ainda uma percentagem significativa de artistas estrangeiros a trabalhar entre nós. Podemos dividir em dois os tipos de edificações religiosas com gárgulas figurativas pertencentes a esse período: por um lado, temos edifícios de charneira e proto-renascentistas, que oscilam entre as duas tendências, quer a nível estrutural, quer decorativo, por outro temos edifícios construídos já sob alguns dos princípios clássicos

\footnotetext{
${ }^{1}$ João Barreira instaura o conceito de "nomadismo artístico" em 1928, no catálogo de Portugal dedicado à Escultura, para a Exposição de Sevilha, mas desenvolve-o na "Arte Portuguesa" no volume dedicado à Arquitectura e Escultura, relativamente ao manuelino; cf. C. F. Barreira 2004 104-105.

${ }^{2}$ C. F. Barreira (2006), "João Barreira, o Manuelino e o conceito de "nomadismo artístico" in Actas do III Congresso Internacional da A.P.H.A. - Portugal na Encruzilhada da Cultura, das Artes e das Sensibilidades. Porto (in www.apha.pt/boletim4/defaultt.htm).
} 
que caracterizaram o Renascimento, como o Claustro da Manga, que vamos desenvolver.

Dentro dos edifícios de charneira e dos proto-renascentistas verificamos ainda dois tipos de situação no que concerne às gárgulas: a realização de um programa iconográfico "de raiz", como na Matriz de Torre de Moncorvo,

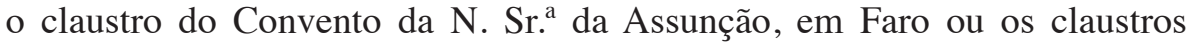
levantados por João de Castilho no Convento de Cristo em Tomar. Dada a extensão do assunto, não podemos aqui desenvolvê-lo, mas ficam as referências, importantes porque as gárgulas mantiveram uma certa valorização.

Por outro lado, temos duas intervenções pontuais, com vista à conclusão de empreitadas antes iniciadas: as gárgulas de João de Castilho em Sta. M ${ }^{\mathrm{a}}$ da Vitória; e a gárgula de Diogo de Torralva, no claustro de Sta. $\mathbf{M}^{\mathrm{a}}$ de Belém (ângulo NO). Estes dois últimos casos são particularmente interessantes porque reflectem uma certa continuidade temática em relação ao programa inicial das gárgulas, embora em ambas as situações se verifique uma actualização formal, mais flagrante em Belém, pois o programa das gárgulas do claustro reporta-se ao universo da Alquimia e da sabedoria hermética (assim como uma boa percentagem da sua decoração, segundo A. Telmo e Paulo Pereira ${ }^{4}$ ). A gárgula com que Torralva finalizou a empreitada, concluindo os dois lanços do piso superior do claustro, passadas mais de duas décadas da realização das outras gárgulas, é uma representação do protagonista da Grande Obra, o Iniciado, que exibe um barrete frígio, atributo do Adepto que identificava o seu portador como conhecedor da filosofia hermética. Esta gárgula atesta em definitivo o conhecimento, por parte de Torralva, da simbólica claustral ligada à linguagem hermética, o que lhe permitiu uma conclusão com continuidade temática.

A continuação da colocação de gárgulas em edifícios de charneira e protorenascentistas está directamente relacionada com a educação dos mestres, quer os nacionais, quer os "nómadas", educados na sua maioria em contexto tardogótico e familiarizados com a sua colocação e com um tipo de gosto que se pode caracterizar como eclético. Mas a resposta também pode ser enriquecida com o estudo das gárgulas do Jardim da Manga, que constitui o núcleo desta nossa comunicação.

\section{As gárgulas do Claustro da Manga}

O Claustro ou Jardim da Manga faz parte do complexo de edifícios do Mosteiro de Sta. Cruz de Coimbra. É constituído por um templete central, que exibe oito gárgulas no entablamento e por quatro capelas-oratórios, de planta cilíndrica, com duas gárgulas cada, a ladear a entrada, num total de dezasseis gárgulas. A partir de uma descrição de D. Francisco de Mendanha, realizada em 1541, às capelas-oratórios (cada uma dedicada a um santo eremita) acediase a partir do edifício central "por pequenas pontes levadiças que uma vez

\footnotetext{
${ }^{3}$ A. Telmo 1997 79-115.

${ }^{4}$ P. Pereira 2004 62-89.
} 
içadas dos eremitérios, permitiam aos religiosos a quebradura de laços com o exterior." 5

A autoria pertence a João de Ruão, como se pode ler no Livro de Receitas e Despesas de Sta. Cruz, de 1534-1535, fl. 18: "Item pagamos a Joham de Ruão e a Jheronymo Afonso cemto e setenta e seis mjll e seiscemtos reais pêra a obra q fizera dos cubelos na crasta terceira da pedraria laurada somente" Esta soma dividiu-se entre 140600 reais para Ruão e 36000 para o português Jerónimo Afonso.

A inovadora planta do claustro revela uma simbólica bastante complexa, constituindo-se como uma metáfora do jardim do paraíso, hortus conclusus, em articulação com noções de Numerologia, e foi fruto da iniciativa de Frei Brás de Barros (1500 - 1559) que, desde a segunda década de quinhentos, mais concretamente a partir de 1527 , foi o grande responsável pela reforma do Mosteiro de Coimbra.

Segundo a historiadora da arte Susana Abreu, "este conjunto é uma metáfora do cerne da doutrina de Henrique Hárfio exposta no "Espelho da Perfeycam", ideia com a qual concordamos. Henricus Herp foi um místico franciscano do séc. XV e a sua obra, significativa para as ordens reformadas, foi traduzida por Frei Brás de Barros em 1533. O livro faz a apologia de uma vida eremítica, ascética e despojada, onde cada um deve procurar o desapego ao mundo material, numa procura da perfeição espiritual e da rejeição do pecado.

Nas oito gárgulas do templete central somente uma representa a figura humana, um putti. Todas as outras são híbridos, pertencendo pois à esfera do bestiário. Em relação aos eremitérios, marca presença a figura humana. Vamos tentar problematizar o programa iconográfico articulando aspectos variados, uns ligados a continuidades ou persistências e outros à introdução de novidades.

No que concerne a aspectos que se ligam a persistências formais, temos as gárgulas figurativas enquanto elementos característicos do gótico e do tardogótico, inseridas numa edificação clássica. Como sabemos, o Renascimento adoptou as gárgulas-canhão, ou tubo, que depois serão substituídas pelos algerozes. Ainda neste campo, também encaramos como uma persistência o hibridismo das gárgulas do templete central. Tal hibridismo resultou do uso da analogia inusual, uma técnica criativa, fruto do pensamento analógicometafórico, que se baseia na junção harmoniosa entre diferentes partes

\footnotetext{
${ }^{5}$ Citado por S. M. Abreu 199965.

${ }^{6}$ Citado por V. Correia 1946241.

7 S. M. Abreu 199965.
} 
de diferente seres, muito comum, por exemplo, nos seres fantásticos das iluminuras e dos capitéis.

Em termos estéticos, no Gótico, este hibridismo foi legitimado e discutido pela escolástica através da categoria estética do Feio, enquanto no Renascimento o hibridismo foi conotado com o Grotesco.

Em relação a persistências temáticas, as gárgulas mantiveram aqui a função pedagógica que as havia caracterizado até então, ou seja, também neste contexto funcionaram como exempla e no templete central constituíram uma metáfora da representação dos pecados, expressa pelo bestiário, em que 0 mesmo recupera o importante papel moralizante que havia tido no seu apogeu, pois no séc. XV e inícios do séc. XVI, nas gárgulas, o pecado foi vulgarmente ilustrado através da representação da figura humana. Ainda neste âmbito, a sua inspiração na literatura de origem religiosa, de carácter moralizante, revela-se igualmente como uma forma de persistência temática, embora neste contexto associada ao humanismo reformista.

Mas nas gárgulas do Jardim da Manga também temos importantes actualizações, quer formais, quer temáticas. No campo das novidades formais, estas gárgulas são caracterizadas por uma grande expressividade, que resulta em parte da experiência do próprio artista, que se reflecte nas proporções dos corpos, mais longos, animados por movimento implícito, e na sua autonomia face à estrutura de suporte, quase uma agitação maneirista dos corpos que se contorcionam em pose serpentinata. Estão a uma grande distância plástica das primeiras gárgulas nacionais, que se projectam tão-só das paredes dos edifícios numa perpendicularidade extática, caracterizadas por uma rigidez hierática. A animosidade destas gárgulas torna-as únicas entre nós.

Em relação às novidades temáticas, a mais evidente é a representação do putti, pois é a única gárgula putti que conhecemos. A sua integração com as representações dos pecados devia ser lida na época como indiciadora da sua associação aos mesmos, em particular ao amor carnal e à condenação da sensualidade, da deleitação, do gosto e do tacto que no "Espelho da Perfeycam" Henricus condena veementemente, pois choca com a procura da perfeição espiritual.

Nos eremitérios a protagonista é a figura humana, representada como o homem do quotidiano quinhentista, mas que exibe uma expressão de horror, num rosto deformado: parece-nos que Ruão insistiu na possibilidade que cada homem tem de fuga aos pecados (a convivência do homem com o pecado deformou-lhe a expressão), na sua vocação para ser religioso e por último, na fuga do mundo através do eremitismo e do isolamento espiritual necessários à elevação religiosa.

\section{Notas finais}

Perante este cenário, onde contrapusemos as persistências e as novidades que caracterizam as gárgulas do Claustro da Manga, pretendíamos compreender e justificar a sua presença numa estrutura clássica, edificada sob princípios do Renascimento, mas onde ainda se verificam alguns aspectos medievais. As 
gárgulas evidenciam uma falha na compreensão dos princípios clássicos ou confirmam a importância pedagógica que a sua presença ainda tem perante um público-alvo específico, neste caso a comunidade religiosa masculina dos cónegos regrantes de Sto. Agostinho?

A resposta reside justamente nessa duplicidade, por princípio antagónica, em conjugar aspectos que ainda são herdeiros do universo medieval e tardomedieval, como os aspectos simbólicos da planta e as gárgulas, com a arquitectura clássica.

A fonte da Manga não constitui verdadeiramente um corte face à tradição, mas uma harmoniosa síntese entre continuidades e rupturas. A linguagem usada nesta fons vitae é a da tratadística clássica, modelo de identidade face à reforma que Frei Brás de Barros quer imprimir em Coimbra, ou seja, existe uma clara intenção de associar os valores clássicos aos valores reformistas, através de uma planta que valoriza e articula aspectos como a contemplação, a oração e o eremitismo monástico. Ora estes princípios, derivados de um desejo de renovação espiritual, saem reforçados pela presença das gárgulas cujo programa, de grande pertinência pedagógica, reflecte uma profunda articulação com o seu público-alvo.

\section{Anexos}

Gárgulas do Claustro da Manga. A primeira imagem representa uma gárgula de um eremitério. Todas as outras pertencem ao templete central.

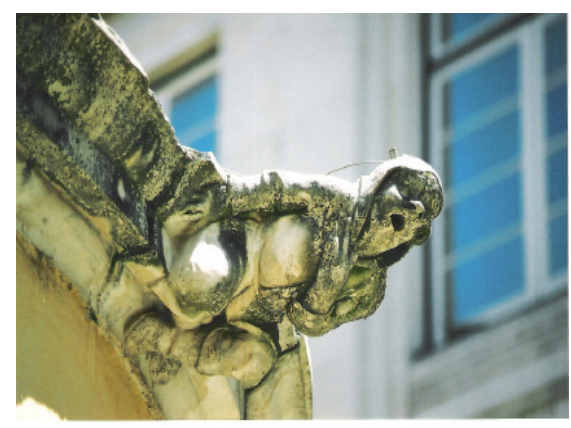

Fig.1 


\section{Catarina Barreira}

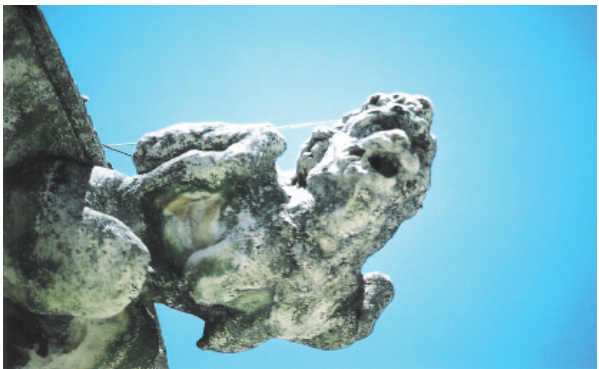

Fig.2

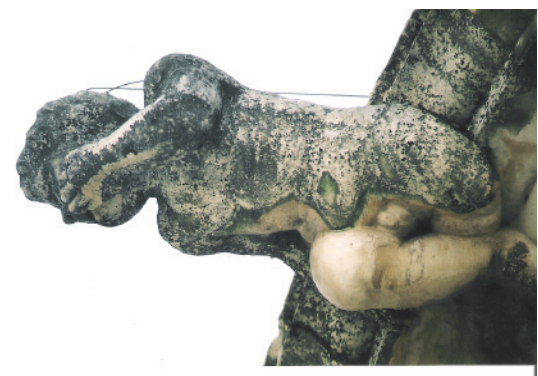

Fig.3

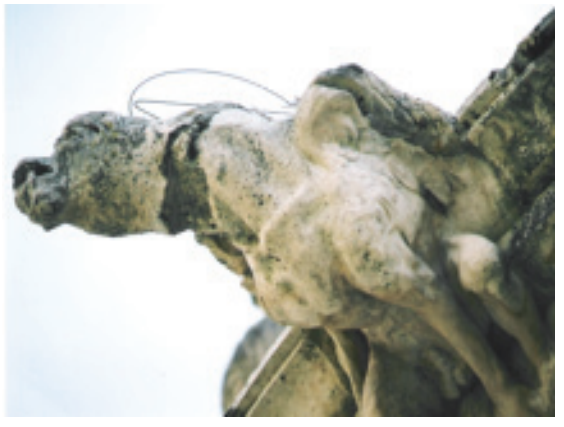

Fig. 4 


\section{Bibliografia}

S. M. Abreu (1999), A Docta Pietas ou a Arquitectura do Mosteiro de S. Salvador também chamado Santo Agostinho da Serra (1537 - 1692). Porto (dissertação de Mestrado em História da Arte em Portugal, Fac. de Letras da Universidade do Porto)

C. F. Barreira (2004), João Barreira e a Historiografia da Arte Portuguesa. Lisboa (dissertação de Mestrado, Faculdade Belas Artes, Universidade de Lisboa).

V. Correia (1946), Obras. 1. Coimbra, Imprensa da Universidade,

H. Hierp (1533), Espelho da perfeyçam: em lingoa portugues. Tradução por Frei Brás de Barros. Coimbra, Moesteyro de Sancta Cruz (Microfilme)

P. Pereira (2004), Enigmas - Lugares mágicos de Portugal. Idades do Ouro. 3. Lisboa, Círculo de Leitores.

A. Telmo (1997), Horóscopo de Portugal. Lisboa, Guimarães Editores. 